\title{
The Non-Linear Effects of Energy Efficiency Gains on the Incidence of Energy Poverty
}

\author{
Raad Al-Tal ${ }^{1}$, Muntasir Murshed ${ }^{2, *}$ (C) Paiman Ahmad $\left.{ }^{3,4}{ }^{(}\right)$, Abdelrahman J. K. Alfar ${ }^{5}$, Mohga Bassim ${ }^{6, *}$, \\ Mohamed Elheddad ${ }^{7}$, Mira Nurmakhanova ${ }^{8}$ and Haider Mahmood ${ }^{9}$
}

1 Department of Economics, The University of Jordan, Amman 11942, Jordan; r.tal@ju.edu.jo

2 School of Business and Economics, North South University, Dhaka 1229, Bangladesh

3 Department of Law, College of Humanity Sciences, University of Raparin, Ranya 46012, Iraq; paiman@uor.edu.krd or payman.ramazan@tiu.edu.iq

4 International Relations and Diplomacy Department, Faculty of Administrative Sciences and Economics, Tishk International University, Erbil 44001, Iraq

5 Department of Economics, The University of Hull, Hull HU6 7RX, UK; a.e.alfar-2018@hull.ac.uk

6 Department of Economics and International Studies, University of Buckingham, Buckingham MK18 1EG, UK

7 Department of Management, Huddersfield Business School, University of Huddersfield,

Huddersfield HD1 3DH, UK; m.m.elheddad@hud.ac.uk

8 Department of Accounting and Finance, KIMEP University, Almaty 050010, Kazakhstan; miranur@yahoo.com

9 Department of Finance, College of Business Administration, Prince Sattam Bin Abdulaziz University, Alkharj 11942, Saudi Arabia; h.farooqi@psau.edu.sa

* Correspondence: muntasir.murshed@northsouth.edu (M.M.); mohga.bassim@buckingham.ac.uk (M.B.)

check for

updates

Citation: Al-Tal, R.; Murshed, M.; Ahmad, P.; Alfar, A.J.K.; Bassim, M.; Elheddad, M.; Nurmakhanova, M.; Mahmood, H. The Non-Linear Effects of Energy Efficiency Gains on the Incidence of Energy Poverty. Sustainability 2021, 13, 11055. https:// doi.org/10.3390/su131911055

Academic Editor:

Enrique Rosales-Asensio

Received: 10 August 2021

Accepted: 3 October 2021

Published: 6 October 2021

Publisher's Note: MDPI stays neutral with regard to jurisdictional claims in published maps and institutional affiliations.

Copyright: (c) 2021 by the authors. Licensee MDPI, Basel, Switzerland. This article is an open access article distributed under the terms and conditions of the Creative Commons Attribution (CC BY) license (https:// creativecommons.org/licenses/by/ $4.0 /)$.

\begin{abstract}
Energy poverty is defined as insufficient access to modern energy resources which are relatively cleaner than the traditionally utilized ones. In this regard, the incidence of energy poverty is particularly higher in the cases of the developing countries across the globe. Accordingly, the chronic energy poverty issues in the developing countries within Sub-Saharan Africa have become a major socioeconomic and environmental concern for the associated governments. Hence, this study aims to evaluate the effects of energy efficiency gains and shocks to other key macroeconomic factors on energy poverty in the context of selected Sub-Saharan African nations. In this study, we measure energy poverty in terms of the lack of access to clean cooking fuels and technologies for the population of the selected Sub-Saharan African countries. The overall findings from the common correlated effects panel regression analysis reveal that energy efficiency gains initially aggravate the energy poverty situation but improve it later on; consequently, a U-shaped relationship between energy efficiency and access to clean cooking fuels and technologies is evidenced. Besides, the predicted threshold levels of energy efficiency are observed to be higher than the average energy efficiency level of the Sub-Saharan African nations. Moreover, the results also portray that economic growth, carbon dioxide emissions, foreign direct investment inflows, and international trade are effective in reducing energy poverty. Conversely, financial development is witnessed to be ineffective in influencing the incidence of energy poverty in this region.
\end{abstract}

Keywords: energy poverty; energy efficiency; cross-sectional dependency; slope heterogeneity; Sub-Saharan Africa

\section{Introduction}

Energy has multifaceted roles to exhibit in terms of facilitating the overall development of an economy [1,2]. Nevertheless, the International Energy Association (IEA) predicted that around 2.6 billion of the global population are adversely impacted by energy poverty [3]. Energy poverty is conventionally interpreted as insufficient access to modern and cleaner energy resources at low prices [4]. Therefore, enhancing access to these energy resources can also be hypothesized to play a major role in mitigating overall poverty within an economy [5]. In relevance to achieving the Sustainable Development Goals (SDG) 
agenda, the seventh SDG (SDG7) has called upon the global economies to improve access to affordable, reliable, sustainable, and modern energy for their respective populations. Consequently, it can be thought that alleviating energy poverty is one of the major means through which the objectives of the 2030 SDG agenda of the United Nations can be realized.

In comparison to developed nations, the energy poverty scenario is relatively concerning for underdeveloped economies due to the developing nations being traditionally reliant on unclean fossil fuels. The fossil fuel dependency in these nations can be expected to give them a comparative advantage in terms of being able to generate electricity using the indigenous fossil fuels at a relatively cheaper rate than producing electricity utilizing the modern renewable energy sources. Under such circumstances, the energy poverty scenario, using the electrification rate as an indicator, may reflect the true state of energy poverty. This is because in countries such as China, in spite of ensuring $100 \%$ electrification rate, lack of access to modern and cleaner energy for the population classifies China as energy poor; particularly taking the adverse environmental consequences of fossil fuel use into consideration. In line with this notion, it can be said that due to the extensive reliance of the developing countries on traditional fossil fuels for meeting their respective energy demands, their energy poverty reduction performances are not so impressive.

Mitigating energy poverty, apart from achieving energy security, is of paramount importance for the developing nations in order to attain the targets of SDG13, which aims to establish environmental sustainability worldwide [6]. This is because a decline in the energy poverty level is synonymous with a reduction in the use of conventional fossil fuels which, in turn, can be expected to curb the fossil fuel consumption-induced greenhouse gas emissions to restore environmental well-being $[7,8]$. On the other hand, as far as the human health impacts of energy poverty are concerned, it is acknowledged in the literature that the energy-poor countries often depend on unclean fuels for cooking purposes. Therefore, exposure to harmful emissions stemming from the combustion of those unclean cooking fuels is likely to inflict detrimental consequences to human health, especially worsening the health of women [9]. Moreover, transitioning from unclean to cleaner cooking fuels, as a mechanism of energy poverty reduction, is a cumbersome task for the developing nations, considering that these nations face multidimensional constraints that have traditionally upheld the clean cooking fuel transition [10].

The issue of extreme energy poverty has become a major concern for the Sub-Saharan African (SSA) nations as the majority of the population living in this region are characterized as energy poor [11]. As far as access to electricity is concerned, the average rate of electrification across the SSA countries is merely $43 \%$ as opposed to the corresponding global electricity access rate of more than $85 \%$ [12]. Besides, since the majority of the SSA nations are fossil fuel dependent, it is evident that the access to electricity generated from the modern cleaner energy sources is also significantly low. As per the World Bank [13] estimates, the average share of fossil fuel in the aggregate electricity output of the SSA nations was around $65 \%$, which reflects the prevalence of energy poverty across this region. Besides, on average, almost $50 \%$ of the aggregate electricity output of the SSA countries is generated from combusting coal [13]. In addition, almost 900 million people (approximately $85 \%$ of the population) in this region are without access to clean cooking fuels [14]. Accordingly, the existing literature has highlighted the health concerns associated with the use of unclean cooking fuels across Africa [15,16]. Besides, 10 of the top-20 global economies with outrageously large shares of the respective population not having access to clean modern fuels for cooking purposes belong to the SSA region [14].

Furthermore, it is believed that the level of energy poverty across the SSA region has aggravated over the years courtesy of the high population growth rates in the associated countries as opposed to the slow growths in the overall supplies of energy, let alone clean energy supplies. At the same time, the conventional energy resources employed in these countries are of low-efficiency levels [4]. Accordingly, the industrial processes of these nations have traditionally been highly energy-intensive with low levels of energy efficiency [17]. Moreover, compared to developing countries belonging to East Asia and 
the Pacific, Europe and Central Asia, Latin America and the Caribbean, and the Middle East and North Africa, the average energy efficiency level of the SSA developing countries is relatively lower [13]. On the other hand, the inefficient use of energy across the SSA region can also be understood in the context of the low levels of energy intensity. Although the global energy intensity levels have increased between 2010 and 2018, the rate of improvement in the intensity of energy use has been the lowest in the SSA nations [14].

Hence, underscoring the relevance of alleviating energy poverty, this study aims to scrutinize the impacts of energy efficiency improvement and other key macroeconomic aggregates on the level of energy poverty in 36 SSA countries between 2000 and 2016. This study is motivated by the prediction that the overall energy demand in Africa would increase by a staggering 85\% over the 2010-2040 period [18] which, in turn, is expected to further aggravate the energy poverty scenario across this region. Besides, given the majority of the SSA nations are predominantly fossil fuel-dependent, it is pertinent to assess whether energy efficiency gains can be effective in mitigating the degrees of energy poverty in the economies of concern. Additionally, the outcomes from this study are expected to unearth critically important energy policy implications in respect of improving energy efficiency levels with the aim of ensuring energy security through energy poverty alleviation. Moreover, this study is also relevant from the perspective of attaining several of the SDG by the selected SSA nations.

This current study contributes to the literature in several ways. Firstly, this study evaluates the accessibility to modern energy resources dimension of energy poverty in the SSA countries context. The preceding studies have conventionally measured energy poverty in terms of electricity access rate for the population of the respective SSA nations $[19,20]$. Besides, the energy poverty analysis for the cases of the SSA and other developing countries has been extensively analysed at the household level [21,22]. As opposed to the approaches adopted in these preceding studies, this current study uses the access to clean fuels and technology for cooking rates of 36 SSA countries to proxy for energy poverty and conducts the analysis at the macroeconomic level. Secondly, to the best of the authors' knowledge, this is the seminal study that scrutinizes the impacts of energy efficiency gains on the energy poverty levels of the selected SSA nations. However, improving energy efficiency is often recommended as a means of reducing energy poverty [23,24]. It is of greater relevance for the SSA countries because the energy demand across this region is said to be persistently growing with time; however, the energy supplies, both traditional and modern ones, are not likely to match the rate of growth in energy demand. Under such adverse circumstances, energy efficiency can be hypothesized to work as demand-side management of energy poverty in this region. Lastly, this further contributes to the literature by exploring the possible non-linearity of the energy efficiency-energy poverty nexus. This is important because energy efficiency gains within the developing countries in particular may not be initially sufficient for curbing energy poverty; however, persistent improvement in energy efficiency can be expected to eventually mitigate energy poverty in these nations.

The subsequent sections chronologically summarize the relevant literature, highlights the empirical model, and describes the data attributes used in this study, discuss the econometric methodology employed, report and analyse the findings, and conclude with precise policy recommendations.

\section{Literature Review}

Although there is no universal definition of energy poverty, the existing studies have predominantly viewed energy poverty as lack of access to energy resources in general. However, in modern times, simply enhancing energy access rates is not sufficient in addressing the energy poverty reduction challenges. Hence, apart from increasing energy access, it is also necessary to enhance access to modern and cleaner energy resources. Yet, the existing literature is saturated with studies that have evaluated the macroeconomic determinants of energy poverty in respect of the overall access to energy resources for a given population. Among these, Trotter [19] used annual data from 1990 to 2010 for 46 SSA 
countries to evaluate the determinants of rural electrification. The authors measured energy poverty in terms of the rural electrification rates and the ratios of rural and urban electrification rates and found that good governance is pertinent for curbing energy poverty in the rural areas of the selected SSA nations. In another study featuring South Africa, Sarkodie and Adams [20] used the overall electrification rate to indicate the level of poverty in South Africa between 1990 and 2017. The findings portrayed that greater economic growth and income inequality enhances energy poverty while controlling corruption is effective in reducing energy poverty in this SSA country. Similarly, referring to electricity access as a measure of energy poverty from the SSA countries perspective, Falchetta et al. [25] recently opined that private investments in the electricity sector is crucial for achieving a $100 \%$ electrification rate; accordingly, the authors highlighted the need for mitigating regulatory, market, and governance risks to further enhance the access to electricity for the people in this region.

Similar studies on energy poverty have also been conducted for non-SSA nations. In a study on 80 villages in the Bihar district of India, Oda and Tsujita [26] concluded that rural electrification rate is high across villages that are in proximity to the national grid while low electrification rate was prominent for remote villages. Similarly, in the context of Brazil, Goldemberg et al. [27] asserted that initiating relevant electrification policies reforms and overcoming the institutional and regulatory barriers is necessary for expanding electricity access across the rural neighbourhoods of Brazil. In another relevant study on Small Island Developing States of the Pacific, Dornan [28] argued that regulatory reforms within the energy sector facilitate rural electrification. Besides, the authors also concluded that extension of the national grid is not entirely effective in boosting access to electricity for the rural population; rather, off-grid electrification initiatives are more appropriate in improving electricity access across rural areas.

A plethora of the preceding studies have analysed energy poverty at the household levels, especially in the context of developing economies. In the context of the SSA nations, Adusah-Poku and Takeuchi [29] used national household survey data for Ghana and found that access to electricity, within the rural households, is positively determined by higher household expenditure levels, the employed status of the household members, and the gender of the household's head. In another study on the household energy poverty determinants in Senegal and Togo, Gafa and Egbendewe [30] stated that energy poverty, in terms of the affordability to consume energy resources, is reduced when women and men make joint decisions concerning the purchase of energy resources. Besides, the authors also claimed that affordable pricing of energy resources is effective in curbing the energy poverty levels further. Apart from these two factors, the authors stressed that household income level and fertility also determine the incidence of energy poverty within the rural households of Senegal and Togo. On the other hand, Ashagidigbi et al. [31] used the ratio of energy-poor households in the total number of households to measure energy poverty in Nigeria and found that energy poverty is determined by the location of the household as rural households were evidenced to be relatively more energy-poor compared to the urban households. Besides, male-headed households and an older household head were identified as the key drivers of energy poverty in Nigeria. In contrast, higher household income levels and access to microfinance were asserted to be effective in curbing energy poverty.

As far as the determinants of energy poverty within the households of non-SSA countries are concerned, Kemmler [32] evaluated the determinants of household energy access to scrutinize the factors influencing the degree of energy poverty in India. The authors claimed that the government of India reports inflated official electrification rates in Indian villages. The findings also revealed that household electrification in rural areas of India largely depends on specific household characteristics, the extent of electrification within a community, and the quality of electricity supplies. Additionally, household expenditure level and traffic imposed on electricity consumption were found to exert nominal influences on access to electricity amidst the households. In another study on Pakistan, Qurat-ul-Ann 
and Mirza [33] also proxied energy poverty using the ratio of energy-poor households in the total number of households and found that households that are male-headed, foreign remittance-recipients, and are in proximity to the nearest markets are more likely to be energy poor. Conversely, Pakistani households with elderly and more educationally qualified household heads are less likely to be energy poor. Recently, Drescher and Janzen [34] concluded that household energy poverty in Germany is determined by the educational qualifications and employment status of the household members. Besides, the authors added that energy-efficient housing arrangements are also effective in reducing energy poverty within German households.

Several studies have also modelled the determinants of household fuel choices to understand the factors which affect the affordability dimension of energy poverty. It is believed that affordability concerning the consumption of clean cooking fuels is a key aspect of energy poverty. It has been acknowledged that switching to cleaner cooking fuels is not only effective in curbing energy poverty across the SSA economies but also has health and environmental benefits [35]. Accordingly, the fuel-switching behaviours among the SSA households were explored. Wassie et al. [36] remarked that rural households in Ethiopia are predominantly reliant on biomass for cooking purposes. However, the authors emphasized that the transition to cleaner cooking fuel alternatives among these rural households is influenced by the distance covered for harvesting firewood. Besides, households with higher income levels and educational achievements were said to be more likely to consume cleaner cooking fuels. In an another study on household energy poverty at the household level, Behera and Ali [37] showed that traditional solid cooking fueldependency of households across the SSA region depends on the gender of the household head and the location of the household; male-headed and rural households were said to be more likely to use the unclean cooking fuel sources while wealthy and educated households are more likely to use the cleaner alternatives. Furthermore, the authors also mentioned that the probability of consuming cleaner cooking fuels is relatively higher for households living close to the market.

Using household data on Nigerian households, Nwaka et al. [38] concluded that compared to de-jure female-headed households, the probability of using cleaner cooking fuels is relatively higher for de-facto male and female-headed households. On the other hand, referring to Liquefied Petroleum Gas (LPG) as a relatively cleaner cooking fuel for households in Cameroon, Pope et al. [39] highlighted that those households with higher educational qualifications and greater ownership of assets and wealth increase the probability of switching from the use of traditional solid cooking fuels to LPG. Twumasi et al. [40] also analysed the energy poverty scenario in the context of Ghanaian households and found that apart from certain household characteristics and socioeconomic factors, higher access to credit motivates the household to use cleaner cooking fuels such as LPG and kerosene. Besides, Olang et al. [41] opined that the choice of cooking fuels for the Kenyan household depends on the location of cooking. Moreover, the authors also advocated in favour of enhancing access to modern fuels for cooking and lighting purposes is necessary for reducing household energy poverty in Kenya.

Apart from the SSA nations, similar household-level energy poverty studies were also conducted for the developing nations outside Africa. In the context of Afghanistan, Paudel et al. [42] found evidence of household poverty reduction and higher educational qualification of the household members enhance the probability of using cleaner cooking fuels while households with aged household heads and a higher number of family members are more likely to rely on the traditional unclean cooking fuels. In another relevant study for the case of India, Sharma et al. [43] asserted that the willingness of households to pay for LPG for cooking purposes positively correlates to the monthly income level of the respective households. Besides, the authors also added that a lower distance between the household's location and the LPG selling agencies also increases the possibility of using LPG among the Indian households. Furthermore, it was also mentioned that the Indian household's decision to switch to LPG was mostly taken by the female household members; 
this portrayed a gendered impact concerning energy poverty reduction in India. Similarly, Imran and Ozcatalbas [44], in the context of Pakistan, concluded that greater access to LPG is one of the prime factors which motivate households to switch from the use of solid biomass and crop residues to LPG for cooking purposes.

Likewise, Acharya and Marhold [45] showed that higher education levels of the household members are likely to facilitate the adoption of LPG as a cleaner cooking fuel while house ownership was said to enhance the probability of using the traditional cooking fuels. Moreover, greater access to information and communications technology was also remarked as stimulating the adoption of LPG in Nepal. In another relevant study for Indonesia, Andadari et al. [5] claimed that enhancing access to LPG for Indonesian households is an effective means of mitigating energy poverty. The study evaluated the impact of the government's decision to execute an LPG adoption program on the cooking fuel-switching behaviour within Indonesian households. The findings revealed that the initiative motivated the households in Indonesia to replace the use of kerosene with LPG for meeting their cooking fuel demand. Liao et al. [46] pointed out that although China has ensured a $100 \%$ electrification rate, this scenario does not provide a clear understanding of the nation's energy poverty scenario as a significant proportion of the Chinese population still uses firewood and other traditional solid cooking fuels. Hence, considering the affordability and accessibility of modern cooking fuels, China can be considered energy poor. Among the other key findings, the authors asserted that a transition from farm to non-farm employment is associated with a transition from traditional to modern cooking fuels as well. However, the gender of the household head and the size of the household were said to be ineffective in facilitating the clean cooking fuel transition.

Therefore, it is clear from the above-mentioned studies that the energy poverty-related studies in the context of the SSA nations have mostly focused on the electrification rates as a measure of energy poverty. Consequently, the access to cleaner energy resources aspect of energy poverty is yet to be extensively explored in the literature. On the other hand, the literature review also suggests that the energy poverty analysis for the SSA nations has largely been conducted at the household level which is evident from the plethora of the preceding studies on the clean cooking fuel-switching mechanisms within the SSA households. However, it is also important to assess this aspect of energy poverty at the macroeconomic level which has largely been overlooked in these studies. Macroeconomic analysis of the determinants of energy poverty is important because it would help us to understand how the energy systems in the SSA nations, as a whole, function to manage the aggregate demand and supply of modern energy resources for the overall population of the respective economies. This is also important from the perspective of relevant public policy-making purposes since government policies are often conceptualized to maximize collective well-being rather than specifically focusing on each individual within the economy. Furthermore, the review of the literature also portrays that none of the previous studies have explored the impacts of energy efficiency gains on the energy poverty figures of the SSA countries. Hence, to address these gaps in the literature, this study scrutinizes the impacts of energy efficiency gains and other macroeconomic variables on the rate of access to clean fuels and technologies for cooking purposes in the context of 36 SSA countries between 2000 and 2016.

\section{Empirical Model and Data}

\subsection{Empirical Model and Data}

Considering the modern energy access aspect of energy poverty, we use the access to clean energy and technology for cooking figures of the selected SSA nations to proxy for energy poverty across this region. In our baseline model, we express this variable as a linear function of energy efficiency, economic growth, Carbon dioxide $\left(\mathrm{CO}_{2}\right)$ emissions, Foreign Direct Investment (FDI) inflows, trade openness, and financial development. The selection of the explanatory variables is based on the underlying theoretical underpinnings. The baseline model can be shown as:

$\mathrm{ACCFT}_{\text {it }}=\beta_{0}+\beta_{1} \ln \mathrm{FF}_{\text {it }}+\beta_{2} \operatorname{lnRGDP}_{\text {it }}+\beta_{3} \operatorname{lnCO} 2_{\text {it }}+\beta_{4} \mathrm{FDI}_{\text {it }}+\beta_{5} \mathrm{OPEN}_{\text {it }}+\beta_{6} \mathrm{FD}_{\text {it }}+\varepsilon_{\text {it }}$ 
where the subscripts $i$ and $t$ refer to the cross-sectional unit and the time period considered in this study, respectively. The parameters $\beta_{0}$ and $\beta_{m}(m=1,2, \ldots, 6)$ are the intercept and the elasticity parameters to be predicted, respectively, while $\varepsilon$ stands for the error term. ACCFT stands for the percentage of the population having access to clean cooking fuels and technologies (ACCFT from hereafter). With regard to energy poverty, a rise in this access rate can be interpreted as a decline in the level of energy poverty and vice-versa.

The main explanatory variable of interest energy efficiency is denoted by EF. Following [47], the efficiency level of energy used is estimated as the value of national output produced per unit of energy employed. An increase in the energy efficiency level is indicative of a rise in the use of energy-efficient energy resources. Hence, energy efficiency gains can be associated with higher ACCFT (i.e., $\beta_{1}>0$ ). The variable lnRGDP refers to the real GDP per capita figures of the SSA nations which are used as a proxy for economic growth within the energy poverty analysis. As an economy grows, it is more likely to employ cleaner energy resources to replace the use of traditional energy resources. Besides, the literature has also confirmed that higher household income facilitates the switch from traditional to modern cooking fuels [36]. Accordingly, at the macroeconomic level, a rise in the national income per capita level can be hypothesized to enhance the ACCFT (i.e., $\beta_{2}>0$ ). The variable $\operatorname{lnCO} 2$ stands for the $\mathrm{CO}_{2}$ emissions per capita figures of the selected SSA nations. A rise in the $\mathrm{CO}_{2}$ emissions level can work as awareness-building to motivate the transition of the consumption of unclean to cleaner fuels [48]. Thus, a rise in the $\mathrm{CO}_{2}$ emissions per capita level can be hypothesized to enhance the ACCFT as well (i.e., $\beta_{3}>0$ ). The variable FDI stands for the share of FDI inflows in the GDP of the SSA nations. Since FDI inflows are often associated with technological spillover in the host economies [49], it can be expected that FDI inflows-induced technological progress can facilitate the rate of access to modern energy resources which require advanced technology to be produced. For instance, LPG production involves the application of the latest technology whereas the extraction and use of traditional solid fuels do not involve the application of such technologies. Accordingly, a rise in the FDI-GDP share can be associated with an improvement in the ACCFT figures (i.e., $\beta_{4}>0$ ).

The variable OPEN stands for the trade openness index which is estimated as a share of exports and imports in the GDP of the respective SSA nation. The decision to include this variable in our model can be rationalized from the understanding that aside from financial globalization, international trade is also important in enhancing access to modern energy resources. For instance, intra-regional trade has been acknowledged as a means of importing cleaner energy resources in the literature [50]. Hence, in this regard, it can be hypothesized that a rise in the trade openness index can also enhance the ACCFT (i.e., $\beta_{5}>0$ ). The variable FD denotes financial development which is measured as a share of credit extended to the private sector in the respective GDP of the SSA nations. Financial development could be thought of as a means of boosting private investments in the clean energy sector [51]. Accordingly, the ACCFT can be enhanced by increasing the level of financial development (i.e., $\beta_{6}>0$ ).

Although energy efficiency gain is often hypothesized to reduce energy poverty by enhancing access to modern and cleaner energy resources, this assertion may not always hold true for the developing nations in particular. This is because, in some developing countries the growth in energy demand is very high whereby a small improvement in the energy efficiency level may not be sufficient in significantly reducing the demand for energy. If the rise in the energy demand cannot be controlled, the developing nations, in particular, would have no option other than to utilize the traditional and unclean energy resources. In contrast, if the energy efficiency improvement is substantially large, the energy demand can be controlled to a larger extent which, in turn, would give the developing countries some time to develop the clean energy production technologies. Consequently, large energy efficiency gains can be anticipated to facilitate the clean energy transition. On the other hand, energy efficiency improvement is also an indicator of an improvement in the technological stock of a nation. Besides, since undergoing clean energy transition 
requires technological innovation and advancement, energy efficiency improvement is likely to enhance the access to clean energy resources. However, since the energy efficiency level of most developing nations is very low, a small improvement in this level may not be enough to facilitate the level of technological innovation required to significantly enhance the clean energy access rates. In contrast, a large improvement in the energy efficiency level, synonymous with a significant degree of technological innovation, can help the developing nations overcome the technological barriers to adoption of clean energy. Therefore, in line with these notions, the effects of energy efficiency gains on ACCFT can be hypothesized as non-linear.

To model the possible non-linearity of the energy efficiency-ACCFT nexus, the baseline model is augmented with the squared term of the energy efficiency variable $\left[(\operatorname{lnEF})^{2}\right]$ which can be shown as:

$$
\mathrm{ACCFT}_{\text {it }}=\beta_{0}+\beta_{1} \operatorname{lnEF}_{\text {it }}+\alpha_{1}\left(\operatorname{lnEF}_{\mathrm{it}}\right)^{2}+\beta_{3} \operatorname{lnRGDP}_{\text {it }}+\beta_{4} \operatorname{lnCO}_{\text {it }}+\beta_{5} \mathrm{FDI}_{\text {it }}+\beta_{6} \mathrm{OPEN}_{\text {it }}+\beta_{7} \mathrm{FD}_{\text {it }}+\varepsilon_{\text {it }}
$$

From Equation (2), the threshold level of energy efficiency can be estimated using the formula:

$$
\text { Threshold level of } \operatorname{lnEF}=\frac{\alpha_{1}}{2\left(\beta_{3}\right)}
$$

In this current study, annual frequency data from 2000 to 2016 for 36 SSA countries are considered (Table 1 provides the list of the SSA countries considered in this study). The missing data issues are addressed using the interpolation method. The relevant variables have been converted into their natural logarithms to estimate the elasticity parameters. Besides, the unit of measurement and the data sources of the variables are provided in Table 2.

Table 1. The list of the SSA nations considered in this study.

\begin{tabular}{cccc}
\hline & \multicolumn{2}{c}{ The Selected SSA Countries } & \\
\hline Angola & Eritrea & Malawi & Senegal \\
Benin & Eswatini & Mali & Sierra Leone \\
Burkina Faso & Ethiopia & Mauritius & South Africa \\
Cabo Verde & Gabon & Mozambique & Sudan \\
Cameroon & Ghana & Namibia & Tanzania \\
Central African Republic & Guinea & Niger & Togo \\
Congo, Dem. Rep. & Kenya & Nigeria & Uganda \\
Congo, Rep. & Lesotho & Rwanda & Zambia \\
Cote d'Ivoire & Madagascar & Sao Tome and Principe & Zimbabwe \\
\hline
\end{tabular}

Table 2. The variables' units of measurement and data sources.

\begin{tabular}{cccr}
\hline Symbol & Variable & Unit & Source \\
\hline ACCFT & $\begin{array}{c}\text { Access to clean fuel and } \\
\text { technologies for cooking }\end{array}$ & \% of population & World Development Indicators [13] \\
\hline EF & Energy Efficiency & GDP per unit of energy & Authors' calculation \\
\hline RGDP & Real Gross Domestic Product & constant 2010 US\$ & World Development Indicators [13] \\
\hline CO2 & Carbon dioxide emissions & metric tonnes per capita & World Global Atlas \\
\hline FDI & $\begin{array}{c}\text { Net inflows of foreign direct } \\
\text { investments }\end{array}$ & \% of GDP & World Development Indicators [13] \\
\hline OPEN & $\begin{array}{c}\text { Trade openness (sum of exports } \\
\text { and imports) }\end{array}$ & \% of GDP & World Development Indicators [13] \\
\hline FD & $\begin{array}{c}\text { Financial development } \\
\text { (domestic credit provided to } \\
\text { private sector by banks) }\end{array}$ & World Development Indicators [13]
\end{tabular}




\subsection{Econometric Methodology}

The econometric methodology is divided into four stages. In the first stage, the data set used is checked for cross-sectional dependency and slope homogeneity problems (Section 3.2.1). Based on the findings, the subsequent econometric techniques are chosen. The second stage involves the analysis of the stationarity properties (Section 3.2.2) while the cointegrating properties among the variables are assessed in the third stage (Section 3.2.3). Finally, the fourth stage involves the estimation of the energy poverty elasticities through regression analysis (Section 3.2.4).

\subsubsection{Econometric Methodology}

Cross-sectional dependence is one of the two major data issues which compromise the estimates of the integration and cointegration properties of the variables of concern [52]. This issue is believed to occur across cross-sectional units due to globalization among the countries considered within the panel data set [53]. Hence, this study uses the Breusch and Pagan [54] Lagrange Multiplier and Pesaran [55] tests of cross-sectional independence. These techniques predict test statistics assuming the null hypothesis of cross-sectional independence of the particular series under consideration. Thus, the statistical significance of these test statistics would reject the null hypothesis to affirm the cross-sectional dependency in the data. The findings from the cross-sectional dependency analysis are displayed in Table 3. The predicted Breusch-Pagan LM and Pesaran CD test statistics for all of the variables are statistically significant at a $1 \%$ significance level; thus, the null hypothesis of cross-sectional independence can be rejected to affirm the cross-sectional dependency issue in the data. This implies that a shock to a particular variable can be expected to exert similar impacts in multiple countries (cross-sectional units) considered within the panel data set. This is an expected finding since the selected SSA nations are regionally globalized through trade and other economic activities. The cross-sectional dependency analysis is followed by the slope homogeneity analysis.

Table 3. Cross-sectional dependency analysis.

\begin{tabular}{ccc}
\hline \multicolumn{3}{c}{ Null Hypothesis: Cross-Sectional Independence } \\
\hline Variable & \multicolumn{1}{c}{ Breusch-Pagan LM Test Stat. } & Pesaran CD Test Stat. \\
\hline ACCFT & $235.130^{* * *}$ & $15.305^{* * *}$ \\
lnEF & $330.500^{* * *}$ & $41.850^{* * *}$ \\
lnRGDP & $395.340^{* * *}$ & $85.340^{* * *}$ \\
lnCO2 & $375.120^{* * *}$ & $75.339^{* * *}$ \\
FDI & $229.340^{* * *}$ & $14.350^{* * *}$ \\
FD & $395.780^{* * *}$ & $78.500^{* * *}$ \\
OPEN & $185.120^{* * *}$ & $6.850^{* * *}$
\end{tabular}

Note: The optimal number of lags is based on Schwarz Information Criterion (SIC); ${ }^{* *}$ denotes statistical significance at $1 \%$ level; statistical significance rejects the null hypothesis of cross-sectional independence.

Similarly to the issue of cross-sectional dependence, slope heterogeneity is another panel data issue that leads to biased estimates of the integrating and cointegrating properties and also affects the efficiency of the long-run elasticity estimates [52]. Although the SSA countries have several common macroeconomic features, they are likely to be heterogeneous in certain aspects. Thus, the slope coefficients can be expected to vary across the cross-sectional units. Hence, this study employs the slope homogeneity testing approach of Pesaran and Yamagata [56]. In this method, two test statistics ( $\Delta$ and $\Delta_{a d j}$.) are predicted under the null hypothesis of slope homogeneity. Hence, the statistical significance of these test statistics would reject the null hypothesis to affirm slope heterogeneity concerns in the data. The results from the Pesaran and Yamagata [56] analysis, as reported in Table 4, reveal that the panel data set used in this study is heterogeneous as perceived from the statistical significance of the predicted test statistics. Based on the findings of the issues of 
cross-sectional dependency and slope heterogeneity, the rest of the econometric strategies are adopted.

Table 4. Slope homogeneity analysis.

\begin{tabular}{ccc}
\hline \multicolumn{3}{c}{ Null Hypothesis: Slope Homogeneity } \\
\hline Test Statistic & Model (1) & Model (2) \\
\hline$\Delta$ & $1.850^{* *}$ & $3.1185^{* * *}$ \\
$\Delta_{a d j .}^{* * *}$ & $2.225^{* *}$ & $3.690^{* * *}$ \\
\hline
\end{tabular}

Note: ${ }^{* * *}$ and ${ }^{* *}$ denote statistical significance at $1 \%$ and $5 \%$ level, respectively.

\subsubsection{Panel Unit Root Analysis}

Conducting the unit root analysis is important for several reasons. Firstly, regression analysis involving non-stationary data (synonymous with data having unit root problems) predicts spurious outcomes [57]. Secondly, the order of integration among the variables included in the model determines the regression strategy that is to be employed [58]. Since the cross-sectional dependency and slope heterogeneity issues have been identified, it does not allow us to employ the traditionally used first-generation panel unit root estimators which assume the cross-sections to be independent. To resolve this issue, the second-generation unit root estimators emerged which take cross-sectional dependency into account while estimating the order of integration of the concerned variables. In this study, we employ the cross-sectionally adjusted Augmented Dickey-Fuller (CADF) and cross-sectionally augmented Im-Pesaran-Shin (CIPS) panel unit root estimators of Pesaran [59]. Both these methods are robust to handling cross-sectionally dependent panel data sets. The unit root analysis is followed by the cointegration analysis.

\subsubsection{Panel Cointegration Analysis}

The cointegration analysis is conducted as a pre-requisite to predicting the long-run elasticities using the relevant panel data regression method. The long-run elasticities can only be estimated in the case of cointegration among the variables in a given model [60]. However, similarly to the case of the panel unit root analysis, the cross-sectional dependency and slope heterogeneity issues invalidate the use of the first-generation cointegration methods. Hence, this study employs the second-generation panel cointegration estimation method of Westerlund [61]. This method is robust when handling cross-sectionally dependent heterogeneous panel data sets and predicts four error correction-based test statistics out of which two are group-mean test statistics $\left(G_{a}\right.$ and $\left.G_{t}\right)$ and two are panel test statistics $\left(\mathrm{P}_{\mathrm{a}}\right.$ and $\left.\mathrm{P}_{\mathrm{t}}\right)$. All of these statistics are estimated under the null hypothesis of non-cointegration among the variables in the respective model. Hence, the rejection of these test statistics confirms the existence of cointegration among the variables. The cointegration analysis follows the panel regression analysis.

\subsubsection{Panel Regression Analysis}

The conventionally employed panel data regression estimators such as the fixed effects, random effects, feasible generalized least squares, panel corrected standard errors, fully modified ordinary least squares, dynamic ordinary least squares, and mean group are inappropriate in the context of cross-sectionally dependent heterogeneous panel data sets. Although most of these estimation techniques account for cross-sectional dependence, the slope heterogeneity issue remains unaccounted for [50]. Consequently, the elasticity parameters predicted using these methods can be considered biased due to the model misspecification issues remaining unaccounted for [62]. Thus, considering the limitations of these techniques, this study uses the Common-Correlated Effects Mean Group (CCEMG) method which was first introduced by Pesaran [63] and later on improvised by Kapetanios et al. [64]. 
The CCEMG method simultaneously accounts for cross-sectional dependency and slope heterogeneity issues. The CCEMG estimator can be derived from the panel data model shown below:

$$
Y_{i t}=\partial_{i}+\delta_{i} X_{i t}+\mu_{i} f_{i}+\rho_{i} \hat{Y}_{i t}+\tau_{i} \hat{X}_{i t}+e_{i t}
$$

where $i$ refers to the cross-sectional unit, $t$ refers to the time period, $Y_{i t}$ is a vector of the outcome variable, $X_{i t}$ is a vector of explanatory variables, $\partial_{i}$ is the intercept, $\delta_{i}$ are the cross-section-specific slope coefficients, $\mathrm{f}_{\mathrm{i}}$ refers to the unobserved common factors with the heterogeneous elements, and $e_{i t}$ is the error-term. From Equation (4), the CCEMG estimator is estimated as the average of the cross-section-specific slope coefficients for each individual regression analysis. The CCEMG $\left(\gamma_{C C E M G}\right)$ estimator can be expressed as:

$$
\gamma_{C C E M G}=N^{-1} \sum_{i=1}^{N} \hat{\beta}_{i}
$$

To check the robustness of the elasticity estimates, we also use the Augmented Mean Group (AMG) estimator of Eberhardt and Bond [65] to estimate the regression models. Similarly to the the CCEMG method, the AMG technique also accounts for both the cross-sectional dependency and slope heterogeneity issues in the data.

\section{Empirical Results and Discussions}

This section begins by analysing the findings from the unit root and cointegration analyses followed by interpreting the elasticity estimators predicted using the CCEMG and AMG analysis. Subsequently, the long-run elasticity findings are discussed.

\subsection{The Panel Unit Root and Cointegration Results}

Table 5 reports the findings from the CADF and CIPS panel unit root tests. Both these tests predict test statistics under the null hypothesis of the particular of concern having a unit root (i.e., the series is non-stationary). The predicted CADF and CIPS test statistics for all of the variables are observed to be statistically insignificant at level I(0). However, at the first difference, I(1), all of the variables become stationary which can be asserted from the statistical significance of the estimated CADF and CIPS test statistics, at $1 \%$ level of significance. Hence, in line with these findings, we can claim that the variables are not mean-reverting at the level form, but they become mean-reverting at the first difference. Consequently, the variables considered in this study have a common order of integration of I(1). Following the unit root analysis, we predict the long-run associations among the variables using the relevant panel cointegration estimator.

Table 5. The panel unit root results.

\begin{tabular}{ccccc}
\hline \multicolumn{4}{c}{ Null Hypothesis: Series Is Non-Stationary } \\
\hline \multirow{2}{*}{ Variables } & CADF & CIPS \\
\cline { 2 - 5 } & Level, I(0) & First Difference, I(1) & Level, I(0) & First Difference, I(1) \\
\hline ACCFT & -1.063 & $-2.243^{* * *}$ & -1.800 & $-3.490^{* * *}$ \\
lnEF/(lnEF) & -1.120 & $-2.450^{* * *}$ & -1.769 & $-3.015^{* * *}$ \\
lnRGDP & -1.599 & $-2.347^{* * *}$ & -1.686 & $-3.313^{* * *}$ \\
lnCO2 & -1.369 & $-2.784^{* * *}$ & -1.970 & $-3.336^{* * *}$ \\
FDI & -1.907 & $-2.807^{* * *}$ & -1.251 & $-4.198^{* * *}$ \\
FD & -1.595 & $-2.397^{* * *}$ & -1.426 & $-3.351^{* * *}$ \\
OPEN & -0.787 & $-2.471^{* * *}$ & -1.120 & $-4.025^{* * *}$ \\
\hline
\end{tabular}

Note: The optimal lags section is based on SIC; ${ }^{* * *}$ reject the null hypothesis of non-stationarity of the series at $1 \%$ level of significance.

Table 6 presents the findings from the Westerlund [61] cointegration analysis. Cointegration among the variables included in the model signifies long-run associates between 
them. The statistical significance of the predicted test statistics from the Westerlund [61] cointegration analysis reject the null hypothesis of non-cointegration to confirm the presence of cointegrating equations within both the models used in this study. Hence, the findings reveal that there are long-run associations between ACCFT, energy efficiency level, economic growth, $\mathrm{CO}_{2}$ emissions, FDI inflows, international trade, and financial development in the context of the selected SSA nations. This implies that these variables move together in the long-run. Besides, the long-run cointegrating relationships between the variables fulfil the pre-requisite of estimating the long-run elasticity parameters using the appropriate panel data regression estimators.

Table 6. The panel cointegration results.

\begin{tabular}{ccccc}
\hline \multicolumn{5}{c}{ Null Hypothesis: Non-Cointegration } \\
\hline Model & Ga & Gt & Pa & Pt \\
\hline (1) & 1.630 & $-3.450^{* * *}$ & $-1.550^{*}$ & $-3.020^{* * *}$ \\
$(\mathbf{2})$ & 1.145 & $-3.100^{* * *}$ & $-1.450^{*}$ & $-2.790^{* * *}$ \\
\hline
\end{tabular}

Note: The optimal lags section is based on SIC; *** and * reject the null hypothesis of non-cointegration at $1 \%$ and $10 \%$ levels of significance, respectively; the test statistics are predicted using 5000 bootstrapped replications.

\subsection{The Panel Regression Findings}

Following the confirmation of the long-run associations between the variables of concern, the long-run elasticity parameters are estimated using the CCEMG and AMG estimators, which are reported in Table 7 . Overall, the estimates are robust across the two alternative methods employed in this study since the predicted signs in both cases are identical. In the context of Model (1), energy efficiency gains are not effective in reducing energy poverty in the selected SSA. A rise in the energy efficiency level by $1 \%$ is witnessed to reduce the ACCFT by around $17.08-20.10 \%$, on average, ceteris paribus. Therefore, it can be concluded that the overall energy efficiency gains cannot influence the clean cooking fuel transition. However, in the context of model (2), we find evidence of persistent gains in energy efficiency being effective in tackling the energy poverty level by increasing the ACCFT. This phenomenon is confirmed by the positive sign of the statistically significant elasticity parameter attached to the squared term of the energy efficiency variable $\left[(\operatorname{lnEF})^{2}\right]$.

The elasticity estimates show that beyond the threshold energy efficiency level, a 1\% improvement in the level of energy efficiency results in a decline in the ACFT by $3.07-4.73 \%$, on average, ceteris paribus. Therefore, it can be said that the energy efficiency-ACCFT nexus is U-shaped, which implicates that persistently improving the energy efficiency level can be deemed necessary to mitigate energy poverty in the SSA nations. As per the predicted elasticities, the threshold level of energy efficiency is estimated at around 13.89-17.84 PPP US\$ per $\mathrm{kg}$ of oil equivalent energy use. It is to be mentioned that the average energy efficiency level of the selected SSA nations is merely 8.26 PPP US $\$$ per kg of oil equivalent energy use. Therefore, it can be observed that the average energy efficiency level of the SSA nations is below the predicted energy efficiency thresholds which can be used to logically explain why the ACCFT levels of the SSA nations have traditionally been low. Hence, eradicating energy poverty in terms of enhancing ACCFT requires the SSA nations to persistently increase their respective energy efficiency levels so that the threshold average energy efficiency level can be achieved.

As far as economic growth is concerned, the results show that the growth of the selected SSA economies is necessary for reducing the incidences of energy poverty. A $1 \%$ rise in the real GDP per capita level is found to be associated with a rise in the ACCFT by $25.02-30.62 \%$, on average, ceteris paribus. The positive nexus between economic growth and ACCFT indicates that as the economies of the SSA nations grow, these nations are economically empowers to overcome the barriers that have traditionally inhibited the prospects of reducing unclean fuel dependency and enhancing access to clean fuels for cooking purposes. This finding corroborates the findings were reported by Murshed et al. [66] in the context of the developing countries from South Asia. Similarly, the elasticity esti- 
mates also reveal that environmental degradation is one of the key macroeconomic factors responsible for reducing energy poverty. The corresponding elasticity estimates indicate that a $1 \%$ rise in the $\mathrm{CO}_{2}$ emissions per capita figures is responsible for a rise in the ACCFT by $6.32-9.03 \%$, on average, ceteris paribus. This is similar to the findings of the study by Omri and Nguyen [67] in which the authors concluded that the aggravation of the level of $\mathrm{CO}_{2}$ emissions boosts the modern renewable energy consumption levels. Hence, it can be said that as the volume of $\mathrm{CO}_{2}$ emissions increase, the SSA nations can be expected to be terrified by the adverse environmental consequences associated with $\mathrm{CO}_{2}$ emissioninduced climate change. As a result, these nations are likely to replace the use of unclean cooking fuels with the relatively cleaner alternatives.

Table 7. The long-run elasticities from the CCEMG and AMG analyses.

\begin{tabular}{|c|c|c|c|c|}
\hline & Model (1) & & Model (2) & \\
\hline Estimator & CCEMG & AMG & CCEMG & AMG \\
\hline \multicolumn{5}{|l|}{ Regressors } \\
\hline $\operatorname{lnEF}$ & $\begin{array}{c}-20.104^{* * *} \\
(2.514)\end{array}$ & $\begin{array}{c}-17.075^{* * *} \\
(1.653)\end{array}$ & $\begin{array}{c}-21.19^{* * *} \\
(3.120)\end{array}$ & $\begin{array}{c}-17.705^{* * *} \\
(1.810)\end{array}$ \\
\hline$(\ln E F)^{2}$ & - & - & $\begin{array}{c}4.027^{* * *} \\
(1.100)\end{array}$ & $\begin{array}{c}3.072 * * * \\
(0.908)\end{array}$ \\
\hline $\operatorname{lnGDPPC}$ & $\begin{array}{c}27.595^{* * *} \\
(2.508)\end{array}$ & $\begin{array}{c}25.020^{* * *} \\
(3.910)\end{array}$ & $\begin{array}{c}30.615^{* * *} \\
(2.515)\end{array}$ & $\begin{array}{c}29.806^{* * *} \\
(3.351)\end{array}$ \\
\hline $\operatorname{lnCO} 2$ & $\begin{array}{c}8.395^{* * *} \\
(2.171)\end{array}$ & $\begin{array}{c}6.323 * * \\
(2.978)\end{array}$ & $\begin{array}{c}9.027^{* * *} \\
(2.266)\end{array}$ & $\begin{array}{c}7.139 * * * \\
(2.614)\end{array}$ \\
\hline FDI & $\begin{array}{c}1.367^{* * *} \\
(0.103)\end{array}$ & $\begin{array}{c}1.351^{* * *} \\
(0.281)\end{array}$ & $\begin{array}{c}1.494^{* * *} \\
(0.081)\end{array}$ & $\begin{array}{c}1.433^{* * *} \\
(0.249)\end{array}$ \\
\hline FD & $\begin{array}{c}0.099 \\
(0.072)\end{array}$ & $\begin{array}{c}0.090 \\
(0.077)\end{array}$ & $\begin{array}{c}0.089 \\
(0.072)\end{array}$ & $\begin{array}{c}0.092 \\
(0.074)\end{array}$ \\
\hline OPEN & $\begin{array}{c}0.126^{* * *} \\
(0.024)\end{array}$ & $\begin{array}{l}0.121^{* *} \\
(0.057)\end{array}$ & $\begin{array}{c}0.085^{* * *} \\
(0.026)\end{array}$ & $\begin{array}{c}0.114^{* * *} \\
(0.049)\end{array}$ \\
\hline Constant & $\begin{array}{c}-192.8^{* * *} \\
(18.30)\end{array}$ & $\begin{array}{c}-179.6^{* * *} \\
(29.24)\end{array}$ & $\begin{array}{c}-192.4^{* * *} \\
(20.68)\end{array}$ & $\begin{array}{c}-182.95^{* * * *} \\
(31.320)\end{array}$ \\
\hline Turning point level of EF & - & - & 13.888 & 17.845 \\
\hline Specification & Linear & Linear & Non-Linear & Non-Linear \\
\hline RMSE & 0.058 & 0.031 & 0.062 & 0.039 \\
\hline Observations & 338 & 338 & 338 & 338 \\
\hline
\end{tabular}

Note: ${ }^{* *}$ and ${ }^{* *}$ denote statistical significance at $1 \%$ and $5 \%$ levels, respectively; the standard errors are reported within the (); RMSE refers to the root mean square error which indicates the residual size of the respective model.

Besides, the elasticity estimates also demonstrate that financial globalization by the SSA nations could be effective in curbing their respective energy poverty level. This can be witnessed from the finding that a $1 \%$ rise in the share of FDI inflows in the GDP leads to a rise in the ACCFT by $1.35-1.49 \%$, on average, ceteris paribus. Since financial globalization involves the inflow of foreign direct investments into the developing nations, in particular, such foreign financing can be expected to stimulate a technological spillover impact which, in turn, is likely to help the SSA nations overcome the technological barriers that impede the enhancement in the ACCFT. Moreover, financial globalization can also be hypothesized to ensure technological innovation in the host economies which can further enhance the ACCFT for the SSA countries. This finding is comparable with the conclusion made in the existing studies that have associated FDI inflows with renewable energy consumption $[68,69]$.

Furthermore, although financial development can be hypothesized to be a means of boosting private sector investment in the energy sector for the development of modern fuel 
production technologies, the elasticity estimates show that financial development cannot explain the variations in the energy poverty levels. The statistical insignificance of the corresponding elasticity parameters affirms this claim. This finding demonstrates that the financial sectors of the SSA nations of concern are probably not developed enough to finance the private sector investments in development of clean cooking fuels and technologies. Hence, in this regard, it is important to green the financial sectors of the SSA countries to help the clean cooking fuel industries develop which, in turn, can be though to enhance the ACCFT. Lastly, the predicted elasticity parameters also reveal that international trade can be a means of reducing energy poverty in the selected SSA nations. A rise in the trade openness indices by $1 \%$ is evidenced to enhance the ACCFT by $0.09-0.13 \%$, on average, respectively. Similarly to this finding, several preceding studies have documented findings in favour of international trade being necessary for importing clean energy resources [50]. The positive trade openness index-ACCFT nexus highlights that the unclean cooking fueldependent SSA nations are likely to import cleaner cooking fuels such as LPG from abroad which can be effective in helping these nations replace the use of traditional cooking fuels with the modern and cleaner cooking fuel alternatives.

\subsection{Discussions on the Findings}

This finding of the U-shaped nexus between energy efficiency and ACCFT is somewhat expected from the perspective that energy efficiency gains have often been acknowledged as an indicator of technological progress, more precisely technological innovation within the energy sector [69]. Hence, initially, a small gain in the energy efficiency level, synonymous with technological development in the preliminary phases, may not be sufficient in enhancing access to modern cooking fuels such as LPG. For instance, the extraction of LPG from natural gas production or during oil refining requires the application of the latest technology $[70,71]$. In contrast, the use of conventional solid biomass and firewood for cooking purposes does not require technological progress to a large extent. In this regard, since the majority of the SSA nations considered in this study are developing countries, the level of technology in these countries can also be expected to be low. This is one of the reasons why traditional fuels are the major cooking fuels used across the SSA nations. However, persistently enhancing the energy efficiency levels, synonymous with a persistent advancement in the technologies applied within the energy sector, is likely to make it easier for the SSA nations to achieve the threshold energy efficiency level and, therefore, produce the modern cooking fuels at a relatively lower cost. Hence, in light of these findings, it can be said that a significant improvement in the level of energy efficiency for it to enhance the overall access to cleaner and modern alternative fuels for cooking purposes is required.

The positive impact of economic growth on the ACCFT level implies that economic growth is a prerequisite for energy poverty alleviation in developing countries in particular. This is because when an economy is in its initial phase of growth, it banks on the traditional energy resources to meet the energy demand. In the same vein, during this period, there is a tendency of employing traditional cooking fuels. However, with growth, these economies can be expected to overcome the barriers which have inhibited the clean cooking fuel transition; thus, in the later stages, economic growth is likely to be translated into a rise in the ACCFT. Since the selected SSA nations are mostly low- and lower-middle-income nations [13], it is justified that these nations are predominantly reliant on solid biomass for cooking purposes. Hence, fostering economic growth can enhance the availability and consumption of cleaner cooking fuels such as LPG.

The global concerns associated with the greenhouse gas emission-induced climate change have triggered the world economies to replace the use of traditional unclean fuels with the modern and cleaner ones. Consequently, the global economies, including the selected SSA nations considered in this study, have pledged under the Paris Agreement to curb their respective emission levels by augmenting environmentally friendly energy resources into their national energy mix [72]. Besides, the SSA countries have also committed 
to making greater use of cleaner fuels, for all purposes, in order to achieve several of the 17 SDG including SDG7 and SDG13, in particular $[73,74]$. Under such circumstances, the finding of higher $\mathrm{CO}_{2}$ emissions positively influencing the ACCFT for the SSA countries of concern implies that these nations are likely to undergo clean cooking fuel transition as their respective $\mathrm{CO}_{2}$ emission figures tend to aggravate. As per the guidelines of the World Health Organization (WHO) (For more information on the WHO's guidelines for classifying clean cooking fuels see http:/ / energyaccessplatform.org/index.php/focus-areas/clean-cooking, accessed on 30 June 2021), biogas, LPG, electricity, and natural gas are clean cooking fuel alternatives to the traditionally combusted solid biomass, kerosene, and firewood. These traditional fuels profusely emit carbon into the atmosphere and are therefore alleged to be major contributors of health and environmental concerns. Thus, the aggravation of the $\mathrm{CO}_{2}$ emission figures is likely to motivate the SSA nations to replace the traditional cooking fuels with the modern and cleaner substitutes which, upon combustion, emit relatively lower volumes of smoke and $\mathrm{CO}_{2}$.

Besides, the statistical evidence regarding greater FDI inflows, resulting in lower levels of energy poverty by enhancing the ACCFT for the SSA nations, can also be considered as a rational finding. This is because enhancing the production of cleaner cooking fuels requires technological progress which can take place through the channel of FDI inflows, especially those associated with energy innovation. Several studies in the literature on the pollution haven hypothesis have remarked that financial globalization could trigger the use of fossil fuels in the FDI-hosting economies, especially the developing ones [75,76]. Nevertheless, many studies have also highlighted the technological spillover impacts of FDI inflows on the clean energy technology development in the host nations $[77,78]$. Furthermore, FDI inflows are also hypothesized to be effective in enhancing the energy efficiency levels of the host-nations $[79,80]$ which, in turn, can be anticipated to further enhance the ACCFT. Hence, in the context of the SSA nations, FDI inflows can be expected to bridge the technological barriers inhibiting greater production of clean cooking fuel; consequently, the energy poverty situation can be improved by enhancing the ACCFT.

On the other hand, the finding of financial development not being able to explain the variations in the ACCFT for the SSA nations implies that the financial sectors in these countries are yet to be developed enough to facilitate private sector investments for clean cooking fuel technology development. It is to be noted that the financial sectors within the developing countries are particularly weak and inefficient. This could be true for the selected SSA countries as well since the majority of these nations belong to the low and lower-middle-income groups [13]. Lastly, the finding of international trade being effective in reducing energy poverty by enhancing the ACCFT for the SSA nations implies that these traditional unclean cooking fuel-dependent nations can import cleaner cooking fuels such as LPG. The prospects of clean energy imports in Africa have also been put forward in the literature $[81,82]$.

\section{Conclusions}

Energy poverty alleviation has become a major global policy agenda to which the SSA nations are no exception. Although energy poverty can embody several forms, inadequate access to modern energy resources is often classified as an indicator of energy poverty. In the context of the SSA nations, the energy poverty scenario can be understood by their predominant reliance on traditional and unclean cooking fuels such as solid biomass, firewood, and kerosene. Besides, the consumption of these fuels has not only compromised the overall well-being of the environment but has also affected the quality of health across this region. Hence, this study evaluated the impacts of energy efficiency gains and other key macroeconomic variables on the incidence of energy poverty in 36 SSA countries over the 2000-2016 period. Diverging from the conventional approach of measuring energy poverty in terms of the electrification rates, this study used the ACCFT as a proxy for energy poverty in order to unearth the macroeconomic factors that can initiate the clean cooking fuel transition in Africa. 
The econometric strategy was designed to account for the cross-sectional dependency and slope heterogeneity issues in the data. The findings from the analysis, in a nutshell, revealed that energy efficiency gains initially reduce the ACCFT while increasing it later on; thus, the energy efficiency-ACCFT nexus depicted a U-shaped relationship. In this regard, the predicted threshold levels of energy efficiency are found to be lower than the average energy efficiency level of the SSA nations taken into consideration. Besides, economic growth, $\mathrm{CO}_{2}$ emissions, FDI inflows, and international trade were identified as key factors responsible for enhancing ACCFT in the SSA countries of concern. However, financial development was found to be ineffective in influencing the ACCFT. In line with these findings, several policy-level suggestions can be put forward in respect of energy poverty alleviation in this region.

Firstly, since the energy efficiency-ACCFT nexus is evidence to portray a U-shaped relationship, it is pertinent for the selected SSA nations to persistently improve their energy efficiency levels. Hence, investment in projects associated with energy innovation can be a credible means of uplifting the existing energy efficiency levels. Besides, investments in research and development for achieving energy efficiency gains can also be considered to enhance the ACCFT further. Accordingly, the implementation of these energy efficiency-enhancing policies can be expected to help the SSA nations achieve the average energy efficiency level required to enhance the ACCFT. Secondly, these nations should also aim at increasing their respective economic growth rates which, in turn, is likely to enhance the ACCFT to initiate the clean cooking fuel transition in this region. However, it must be ensured that the growth policies encourage efficient use of energy within the production processes which would not only expedite the economic growth rates but would simultaneously tackle the energy poverty scenario.

Thirdly, it is important for the SSA countries to enhance awareness regarding the environmental adversities linked with $\mathrm{CO}_{2}$ emissions. If this can be ensured, it can motivate the energy consumers to use energy more efficiently and also replace the consumption of traditional cooking fuels with modern alternatives. Fourthly, it is also essential for the SSA nations to further financially globalize their respective economies, especially by attracting cleaner FDI for the development of clean cooking fuel technologies. Moreover, the FDI should also be directed at projects which can help these nations to improve their energy efficiency levels to further enhance the ACCFT. It can be expected that both energy efficiency gains and greater FDI inflows can jointly help to enhance the ACCFT in the selected SSA countries. Fifthly, these countries should also consider liberalization of the duties and tariffs levied on clean cooking fuel imports to further enhance the ACCFT. In addition, intra-regional trade of modern cooking fuels can also be expected to exert similar impacts across this region. Lastly, the SSA nations should try and develop their financial sectors so that private investments for clean cooking technology development and energy efficiency improvement can be undertaken.

Among the few limitations faced while conducting this study, the unavailability of data restricted the sample size of the SSA nations. Besides, this limitation has also prevented us from conducting country-specific time series analysis of the effects of energy efficiency gains on energy poverty for the individual SSA nations. Such country-specific analysis could have given us an indication whether the energy efficiency-ACCFT nexus is homogeneous or heterogeneous across the SSA nations considered in this study. Besides, another limitation of this study is that only the direct impacts of energy efficiency are considered while the interaction effects (or indirect impacts) of energy efficiency and other key macroeconomic variables on ACCFT are not highlighted. As far as the future research directions are concerned, this study can be extended to assess these possible interaction effects. Moreover, this study can also be replicated for other energy poverty-stricken global regions containing similar developing nations.

Author Contributions: Conceptualization, M.M.; methodology, M.M. and R.A.-T.; software, R.A.-T., P.A. and A.J.K.A.; formal analysis, R.A.-T., M.M., P.A., M.B., M.E. and H.M.; investigation, R.A.-T., P.A. and M.B.; data curation, M.M. and P.A.; writing-original draft preparation, M.M., R.A.-T., M.B. 
and A.J.K.A.; writing-review and editing, M.M., M.B., M.E., M.N. and H.M.; supervision, M.M. and R.A.-T. All authors have read and agreed to the published version of the manuscript.

Funding: This research received no external funding.

Institutional Review Board Statement: Not applicable.

Informed Consent Statement: Not applicable.

Data Availability Statement: The data is publicly available in the World Bank's World Development Indicators repository.

Acknowledgments: We acknowledge the efforts of the anonymous reviewers.

Conflicts of Interest: The authors declare no conflict of interest.

\section{References}

1. Acharya, R.H.; Sadath, A.C. Energy poverty and economic development: Household-level evidence from India. Energy Build. 2019, 183, 785-791. [CrossRef]

2. Amin, A.; Liu, Y.; Yu, J.; Chandio, A.A.; Rasool, S.F.; Luo, J.; Zaman, S. How does energy poverty affect economic development? A panel data analysis of South Asian countries. Environ. Sci. Pollut. Res. 2020, 27, 31623-31635. [CrossRef]

3. Doukas, H.; Marinakis, V. Energy poverty alleviation: Effective policies, best practices and innovative schemes. Energy Sources Part B Econ. Plan. Policy 2020, 15, 45-48. [CrossRef]

4. International Energy Agency. World Energy Outlook 2019. OECD. 2019. Available online: https://www.iea.org/reports/worldenergy-outlook-2019 (accessed on 30 June 2021).

5. Andadari, R.K.; Mulder, P.; Rietveld, P. Energy poverty reduction by fuel switching. Impact evaluation of the LPG conversion program in Indonesia. Energy Policy 2014, 66, 436-449. [CrossRef]

6. Nwozor, A.; Oshewolo, S.; Ogundele, O. Energy poverty and environmental sustainability in Nigeria: An exploratory assess-ment. In IOP Conference Series: Earth and Environmental Science; IOP Publishing: Bristol, UK, 2019; Volume 331, p. 012033.

7. Mundaca, G. How much can CO 2 emissions be reduced if fossil fuel subsidies are removed? Energy Econ. 2017, 64, 91-104. [CrossRef]

8. Mensah, I.A.; Sun, M.; Gao, C.; Omari-Sasu, A.Y.; Zhu, D.; Ampimah, B.C.; Quarcoo, A. Analysis on the nexus of economic growth, fossil fuel energy consumption, $\mathrm{CO} 2$ emissions and oil price in Africa based on a PMG panel ARDL approach. J. Clean. Prod. 2019, 228, 161-174. [CrossRef]

9. Ahamad, M.; Tanin, F.; Shrestha, N. Household Smoke-Exposure Risks Associated with Cooking Fuels and Cooking Places in Tanzania: A Cross-Sectional Analysis of Demographic and Health Survey Data. Int. J. Environ. Res. Public Health 2021, 18, 2534. [CrossRef] [PubMed]

10. Wickramasinghe, A. Energy access and transition to cleaner cooking fuels and technologies in Sri Lanka: Issues and policy limitations. Energy Policy 2011, 39, 7567-7574. [CrossRef]

11. Moss, T. Ending global energy poverty - how can we do better? World Economic Forum, 2019. Available online: https: / / www.weforum.org/agenda/2019/11/energy-poverty-africa-sdg7/ (accessed on 30 June 2021).

12. Blimpo, M.P.; Cosgrove-Davies, M. Electricity Access in Sub-Saharan Africa: Uptake, Reliability, and Complementary Factors for Economic Impact; Africa Development Forum: Casablanca, Morocco, 2019. [CrossRef]

13. World Bank. WDI, World Development Indicators. 2020. Available online: https://databank.worldbank.org/source/worlddevelopment-indicators\# (accessed on 2 December 2020).

14. World Bank. Universal Access to Sustainable Energy Will Remain Elusive Without Addressing Inequalities. The World Bank. 2021. Available online: https:/ / www.worldbank.org/en/news/press-release/2021/06/07/report-universal-access-to-sustainableenergy-will-remain-elusive-without-addressing-inequalities (accessed on 30 June 2021).

15. Karakara, A.A.; Osabuohien, E.S. Clean versus dirty energy: Empirical evidence from fuel adoption and usage by households in Ghana. Afr. J. Sci. Technol. Innov. Dev. 2020, 1-11. [CrossRef]

16. Amadu, I.; Seidu, A.-A.; Afitiri, A.-R.; Ahinkorah, B.O.; Yaya, S. Household cooking fuel type and childhood anaemia in sub-Saharan Africa: Analysis of cross-sectional surveys of 123, 186 children from 29 countries. BMJ Open 2021, 11, e048724. [CrossRef] [PubMed]

17. Davidson, O.R. Energy issues in sub-Saharan Africa: Future directions. Ann. Rev. Energy Environ. 1992, 17, 359-403. [CrossRef]

18. Katrina, P. Examining Energy Efficiency Issues in Sub-Saharan Africa; US Agency for International Development: Washington, DC, USA, 2015. Available online: https:/ / www.usaid.gov/powerafrica/newsletter/dec2014/smarter-power-in-africa (accessed on 30 June 2021).

19. Trotter, P. Rural electrification, electrification inequality and democratic institutions in sub-Saharan Africa. Energy Sustain. Dev. 2016, 34, 111-129. [CrossRef]

20. Sarkodie, S.A.; Adams, S. Electricity access, human development index, governance and income inequality in Sub-Saharan Africa. Energy Rep. 2020, 6, 455-466. [CrossRef] 
21. Rafi, M.; Naseef, M.; Prasad, S. Multidimensional energy poverty and human capital development: Empirical evidence from India. Energy Econ. 2021, 101, 105427. [CrossRef]

22. Crentsil, A.O.; Asuman, D.; Fenny, A.P. Assessing the determinants and drivers of multidimensional energy poverty in Ghana. Energy Policy 2019, 133, 110884. [CrossRef]

23. Dobbins, A.; Nerini, F.F.; Deane, P.; Pye, S. Strengthening the EU response to energy poverty. Nat. Energy 2019, 4, 2-5. [CrossRef]

24. Li, W.; Chien, F.; Hsu, C.C.; Zhang, Y.; Nawaz, M.A.; Iqbal, S.; Mohsin, M. Nexus between energy poverty and energy effi-ciency: Estimating the long-run dynamics. Resour. Policy 2021, 72, 102063. [CrossRef]

25. Falchetta, G.; Dagnachew, A.G.; Hof, A.F.; Milne, D.J. The role of regulatory, market and governance risk for electricity access investment in sub-Saharan Africa. Energy Sustain. Dev. 2021, 62, 136-150. [CrossRef]

26. Oda, H.; Tsujita, Y. The determinants of rural electrification: The case of Bihar, India. Energy Policy 2011, 39, 3086-3095. [CrossRef]

27. Goldemberg, J.; La Rovere, E.L.; Coelho, S.T. Expanding access to electricity in Brazil. Energy Sustain. Dev. 2004, 8, 86-94. [CrossRef]

28. Dornan, M. Access to electricity in Small Island Developing States of the Pacific: Issues and challenges. Renew. Sustain. Energy Rev. 2014, 31, 726-735. [CrossRef]

29. Adusah-Poku, F.; Takeuchi, K. Determinants and welfare impacts of rural electrification in Ghana. Energy Sustain. Dev. 2019, 52, 52-62. [CrossRef]

30. Gafa, D.W.; Egbendewe, A.Y. Energy poverty in rural West Africa and its determinants: Evidence from Senegal and Togo. Energy Policy 2021, 156, 112476. [CrossRef]

31. Ashagidigbi, W.M.; Babatunde, B.A.; Ogunniyi, A.I.; Olagunju, K.O.; Omotayo, A.O. Estimation and determinants of multidimensional energy poverty among households in Nigeria. Sustainability 2020, 12, 7332. [CrossRef]

32. Kemmler, A. Factors influencing household access to electricity in India. Energy Sustain. Dev. 2007, 11, 13-20. [CrossRef]

33. Qurat-Ul-Ann, A.-R.; Mirza, F.M. Determinants of multidimensional energy poverty in Pakistan: A household level analysis. Environ. Dev. Sustain. 2021, 23, 1-45. [CrossRef]

34. Drescher, K.; Janzen, B. Determinants, persistence, and dynamics of energy poverty: An empirical assessment using German household survey data. Energy Econ. 2021, 102, 105433. [CrossRef]

35. Dagnachew, A.G.; Hof, A.F.; Lucas, P.; van Vuuren, D.P. Scenario analysis for promoting clean cooking in Sub-Saharan Africa: Costs and benefits. Energy 2020, 192, 116641. [CrossRef]

36. Wassie, Y.T.; Rannestad, M.M.; Adaramola, M.S. Determinants of household energy choices in rural sub-Saharan Africa: An example from southern Ethiopia. Energy 2021, 221, 119785. [CrossRef]

37. Rahut, D.B.; Behera, B.; Ali, A. Patterns and determinants of household use of fuels for cooking: Empirical evidence from sub-Saharan Africa. Energy 2016, 117, 93-104. [CrossRef]

38. Nwaka, I.D.; Uma, K.E.; Ike, G.N. Determinants of household fuel choices among Nigerian family heads: Are there gen-derdifferentiated impacts? Environ. Sci. Pollut. Res. 2020, 27, 42656-42669. [CrossRef]

39. Pope, D.; Bruce, N.; Higgerson, J.; Hyseni, L.; Stanistreet, D.; Mbatchou, B.; Puzzolo, E. Household Determinants of Liquified Petroleum Gas (LPG) as a Cooking Fuel in SW Cameroon. EcoHealth 2018, 15, 729-743. [CrossRef] [PubMed]

40. Twumasi, M.A.; Jiang, Y.; Ameyaw, B.; Danquah, F.O.; Acheampong, M.O. The impact of credit accessibility on rural house-holds clean cooking energy consumption: The case of Ghana. Energy Rep. 2020, 6, 974-983. [CrossRef]

41. Olang, T.A.; Esteban, M.; Gasparatos, A. Lighting and cooking fuel choices of households in Kisumu City, Kenya: A multidimensional energy poverty perspective. Energy Sustain. Dev. 2018, 42, 1-13. [CrossRef]

42. Paudel, U.; Khatri, U.; Pant, K.P. Understanding the determinants of household cooking fuel choice in Afghanistan: a multi-nomial logit estimation. Energy 2018, 156, 55-62. [CrossRef]

43. Sharma, D.; Ravindra, K.; Kaur, M.; Prinja, S.; Mor, S. Cost evaluation of different household fuels and identification of the barriers for the choice of clean cooking fuels in India. Sustain. Cities Soc. 2020, 52, 101825. [CrossRef]

44. Imran, M.; Ozcatalbas, O. Determinants of household cooking fuels and their impact on women's health in rural Pakistan. Environ. Sci. Pollut. Res. 2020, 27, 23849-23861. [CrossRef]

45. Acharya, B.; Marhold, K. Determinants of household energy use and fuel switching behavior in Nepal. Energy 2019, 169, 1132-1138. [CrossRef]

46. Liao, H.; Chen, T.; Tang, X.; Wu, J. Fuel choices for cooking in China: Analysis based on multinomial logit model. J. Clean. Prod. 2019, 225, 104-111. [CrossRef]

47. Dauda, L.; Long, X.; Mensah, C.N.; Salman, M.; Boamah, K.B.; Ampon-Wireko, S.; Dogbe, C.S.K. Innovation, trade openness and CO2 emissions in selected countries in Africa. J. Clean. Prod. 2021, 281, 125143. [CrossRef]

48. Murshed, M. An empirical analysis of the non-linear impacts of ICT-trade openness on renewable energy transition, energy efficiency, clean cooking fuel access and environmental sustainability in South Asia. Environ. Sci. Pollut. Res. 2020, 27, 36254-36281 [CrossRef]

49. Doytch, N. The impact of foreign direct investment on the ecological footprints of nations. Environ. Sustain. Indic. 2020, 8, 100085. [CrossRef]

50. Murshed, M. Can regional trade integration facilitate renewable energy transition to ensure energy sustainability in South Asia? Energy Rep. 2021, 7, 808-821. [CrossRef] 
51. Kim, J.; Park, K. Financial development and deployment of renewable energy technologies. Energy Econ. 2016, 59, $238-250$. [CrossRef]

52. Dong, K.; Dong, X.; Jiang, Q. How renewable energy consumption lower global CO 2 emissions? Evidence from countries with different income levels. World Econ. 2020, 43, 1665-1698. [CrossRef]

53. Dong, K.; Hochman, G.; Zhang, Y.; Sun, R.; Li, H.; Liao, H. CO2 emissions, economic and population growth, and renewable energy: Empirical evidence across regions. Energy Econ. 2018, 75, 180-192. [CrossRef]

54. Breusch, T.S.; Pagan, A.R. The Lagrange Multiplier Test and its Applications to Model Specification in Econometrics. Rev. Econ. Stud. 1980, 47, 239-253. [CrossRef]

55. Pesaran, M.H. General Diagnostic Tests for Cross-Sectional Dependence in Panels. Empir. Econ. 2021, 60, 13-50. [CrossRef]

56. Pesaran, M.H.; Yamagata, T. Testing slope homogeneity in large panels. J. Econ. 2008, 142, 50-93. [CrossRef]

57. Osabohien, R.; Adeleye, N.; De Alwis, T. Agro-financing and food production in Nigeria. Heliyon 2020, 6, 04001. [CrossRef] [PubMed]

58. Lu, W.-C. Renewable energy, carbon emissions, and economic growth in 24 Asian countries: Evidence from panel cointegration analysis. Environ. Sci. Pollut. Res. 2017, 24, 26006-26015. [CrossRef] [PubMed]

59. Pesaran, M.H. A simple panel unit root test in the presence of cross-section dependence. J. Appl. Econ. 2007, 22, 265-312. [CrossRef]

60. Cai, Y.; Sam, C.Y.; Chang, T. Nexus between clean energy consumption, economic growth and CO2 emissions. J. Clean. Prod. 2018, 182, 1001-1011. [CrossRef]

61. Westerlund, J. Testing for Error Correction in Panel Data. Oxf. Bull. Econ. Stat. 2007, 69, 709-748. [CrossRef]

62. Levin, A.; Lin, C.-F.; Chu, C.-S.J. Unit root tests in panel data: Asymptotic and finite-sample properties. J. Econ. 2002, 108, 1-24. [CrossRef]

63. Pesaran, M.H. Estimation and Inference in Large Heterogeneous Panels with a Multifactor Error Structure. Econometrica 2006, 74, 967-1012. [CrossRef]

64. Kapetanios, G.; Pesaran, M.H.; Yamagata, T. Panels with non-stationary multifactor error structures. J. Econ. 2011, 160, 326-348. [CrossRef]

65. Eberhardt, M.; Bond, S. Cross-Section Dependence in Nonstationary Panel Models: A Novel Estimator (Munich Personal Repec Arch (MPRA), Paper No. 17692). 2009. Available online: https:/ / mpra.ub.uni-muenchen.de/17870/ (accessed on 30 June 2021).

66. Murshed, M.; Abbass, K.; Rashid, S. Modelling renewable energy adoption across south Asian economies: Empirical evidence from Bangladesh, India, Pakistan and Sri Lanka. Int. J. Finance Econ. 2020. [CrossRef]

67. Omri, A.; Nguyen, D.K. On the determinants of renewable energy consumption: International evidence. Energy 2014, 72, 554-560. [CrossRef]

68. Kutan, A.M.; Paramati, S.R.; Ummalla, M.; Zakari, A. Financing renewable energy projects in major emerging market econo-mies: Evidence in the perspective of sustainable economic development. Emerg. Mark. Financ. Trade 2018, 54, 1761-1777. [CrossRef]

69. Bargaoui, S.A.; Liouane, N.; Nouri, F.Z. Environmental Impact Determinants: An Empirical Analysis based on the STIRPAT Model. Procedia Soc. Behav. Sci. 2014, 109, 449-458. [CrossRef]

70. Raslavičius, L.; Keršys, A.; Mockus, S.; Keršienè, N.; Starevičius, M. Liquefied petroleum gas (LPG) as a medium-term option in the transition to sustainable fuels and transport. Renew. Sustain. Energy Rev. 2014, 32, 513-525. [CrossRef]

71. Murshed, M.; Ahmed, R.; Kumpamool, C.; Bassim, M.; Elheddad, M. The effects of regional trade integration and renewable energy transition on environmental quality: Evidence from South Asian neighbours'. Bus. Strategy Environ. 2021. [CrossRef]

72. Yang, F.; Yang, M. Rural electrification in sub-Saharan Africa with innovative energy policy and new financing models. Mitig. Adapt. Strat. Glob. Chang. 2018, 23, 933-952. [CrossRef]

73. Yakovleva, N.; Kotilainen, J.; Toivakka, M. Reflections on the opportunities for mining companies to contribute to the United Nations Sustainable Development Goals in sub-Saharan Africa. Extr. Ind. Soc. 2017, 4, 426-433. [CrossRef]

74. Chirambo, D. Towards the achievement of SDG 7 in sub-Saharan Africa: Creating synergies between Power Africa, Sustainable Energy for all and climate finance in-order to achieve universal energy access before 2030. Renew. Sustain. Energy Rev. 2018, 94, 600-608. [CrossRef]

75. Solarin, S.A.; Al-Mulali, U.; Musah, I.; Ozturk, I. Investigating the pollution haven hypothesis in Ghana: An empirical investigation. Energy 2017, 124, 706-719. [CrossRef]

76. Latief, R.; Lefen, L. Foreign Direct Investment in the Power and Energy Sector, Energy Consumption, and Economic Growth: Empirical Evidence from Pakistan. Sustainability 2019, 11, 192. [CrossRef]

77. Raghutla, C.; Shahbaz, M.; Chittedi, K.R.; Jiao, Z. Financing clean energy projects: New empirical evidence from major in-vestment countries. Renew. Energy 2021, 169, 231-241. [CrossRef]

78. Amoako, S.; Insaidoo, M. Symmetric impact of FDI on energy consumption: Evidence from Ghana. Energy 2021, $223,120005$. [CrossRef]

79. Dong, Y.; Shao, S.; Zhang, Y. Does FDI have energy-saving spillover effect in China? A perspective of energy-biased technical change. J. Clean. Prod. 2019, 234, 436-450. [CrossRef]

80. Pan, X.; Guo, S.; Han, C.; Wang, M.; Song, J.; Liao, X. Influence of FDI quality on energy efficiency in China based on seemingly unrelated regression method. Energy 2020, 192, 116463. [CrossRef] 
81. Matthews, W.G. Opportunities and Challenges for Petroleum and LPG Markets in Sub-Saharan Africa. Energy Policy 2014, 64, 78-86. [CrossRef]

82. Thurber, M.; Moss, T. 12 Reasons why Gas Should Be Part of Africa's Clean Energy Future. World Economic Forum. 2020. Available online: https://www.weforum.org/agenda/2020/07/12-reasons-gas-africas-renewable-energy-future/ (accessed on 30 June 2021). 